\title{
Dollars from Debris
}

\section{Putting the Waste of Yesteryear to Work on the Practical Tasks of Today}

\author{
By William H. Waggaman
}

Bureau of Soils, Washington, D. C.

SOME astute philosopher who probably $S$ had purchased the patent rights to perpetual mótion sagely but sadly remarked that one of the greatest curses inherent to mankind is the desire to obtain something for nothing. The stricken gambler of the stock exchange, the shabby "tout" at the race track, the investor in oilless oil stock, and the suicide who borrowed the bank's funds to clean up on a "sure thing" are typical examples of a weakness which we all possess to a greater or less degree. And yet this tendency when carefully controlled and properly directed is really one of man's greatest assets, and the advance of civilization is to a large extent due to our efforts to turn seemingly worthless material into valuable and useful products.

The United States with its great oil fields, its immense deposits of coal and metal bearing ores, its virgin forests and vast areas of rich agricultural lands has long been the envy of nearly every other nation, but we are waking up to the fact that our wealth and resources are by no means proof against exhaustion. Some of the highest grades and most accessible deposits of ore from which we obtained our copper, lead, and zinc are now little more than memories of the oldest inhabitants. Only deserted ruins mark the location of many rich gold and silver "strikes," which caused thriving towns to spring up in arid wastes. We are burrowing deeper and deeper for our coal supplies. Gigantic oi gushers are now exceptional. No longe can we afford to choose perfect timber for our dwellings or grow the same crops year after year without liberal applications of fertilizers and careful methods of cultivation. In other words the time has come when we must think, plan, invent, and work hard if we are to continue to hold our place as the leading industrial nation of the world. Those of us who still consider ourselves members of the "younger set" recall with a kind of painful pleasur how "father" used to have load after load of anthracite coal delivered at his door or shot into the cellar at the rate of five dollars per ton; and it was coal. Today we almost have to mortgage the old home to obtain from an indifferent dealer a few tons of a product which contains such a high percentage of incombustible what-not that the ashman expects

Various explanations are offered for the increase in price and decrease in the quality of hard coal. Some of them are far from convincing, but one thing is sure and certain-while the demand for coal is growing greater each year the supply is rapidly growing less. In sizing anthracite for the market large tonnages of dust or culm are produced which for years were thrown aside as practically worthless except perhaps for local use under boilers, where constant attention made its burning possible. Though this dust was recognized as perfectly good coal, its shipment was con sidered impractical and the consumer, being used to lump fuel, did not know how to use it For a while only half-hearted experiments were conducted with a view to rendering this slack from our coal mines marketable, but as waste piles grew an mining costs increased real effort was put into these investigations and now methods and equipment have been devised which have cut down this former waste to a minimum.

The powdered-coal burner which sprays pulverized fuel into the fire box or furnace along with a blast of air is finding a wide industrial use. In fact this invention makes it possible to utilize the heat value of coal more fully than when it is burned in lump form. For domestic purposes, an thracite coal dust is now mixed with an

satisfactorily as natural lump ore. The perfection of nodulizing processes has made available immense tonnages of finely divided iron ore formerly considered of little or no economic importance. In some cases other materials which react with or bring about the desired changes in such minerals at high temperatures are mixed and briquetted with the ore and thus more efficient and quicker results are obtained in the furnace than where the various ingredients are each used in large sizes.

Another striking instance of how an almost criminal waste may be at least partially eliminated is afforded by an investigation on the recovery of phosphoric acid from phosphate rock which is being conducted by the Department of Agriculture. Phosphate rock is the basis of the fertilizer industry in this country and though we still have enormous resources of this

oil binder and pressed into briquettes which in many respects are equal if not superior to the regular stove coal. So popular has this type of fuel become within the past few years that in 1918 we consumed nearly one half million tons. This means that we have happily ended an annual loss of at least this much fuel worth at present prices considerably over $\$ 5,000,000$.

COUR short years make a vast difference in outlook. During the war the slogan was "produce, no matter what the cost." We have been through the process of painful awakening and even more painful readjustment, and today we are applying to more and more industries the new demand "cut the cost or quit producing." One way to cut the cost is to recover values which have been allowed to go to waste under the impression that it was either impossible or inconvenient to utilize them. Junk of course we have alnays had with us, and have always got what we could out of it. But the sort of materials with which Mr. Waggaman deals are a little bit more subtle than junk. They are stuff that has never before attained the dignity of junk, but has been allowed rather to flow from the bung-holes of industry without a protest. What Mr. Waggaman tells us is really the story of how this material has been caught en route to the sewer and converted into junk-
or, sometimes, into something even more valuable than junk.- THE EDITOR.

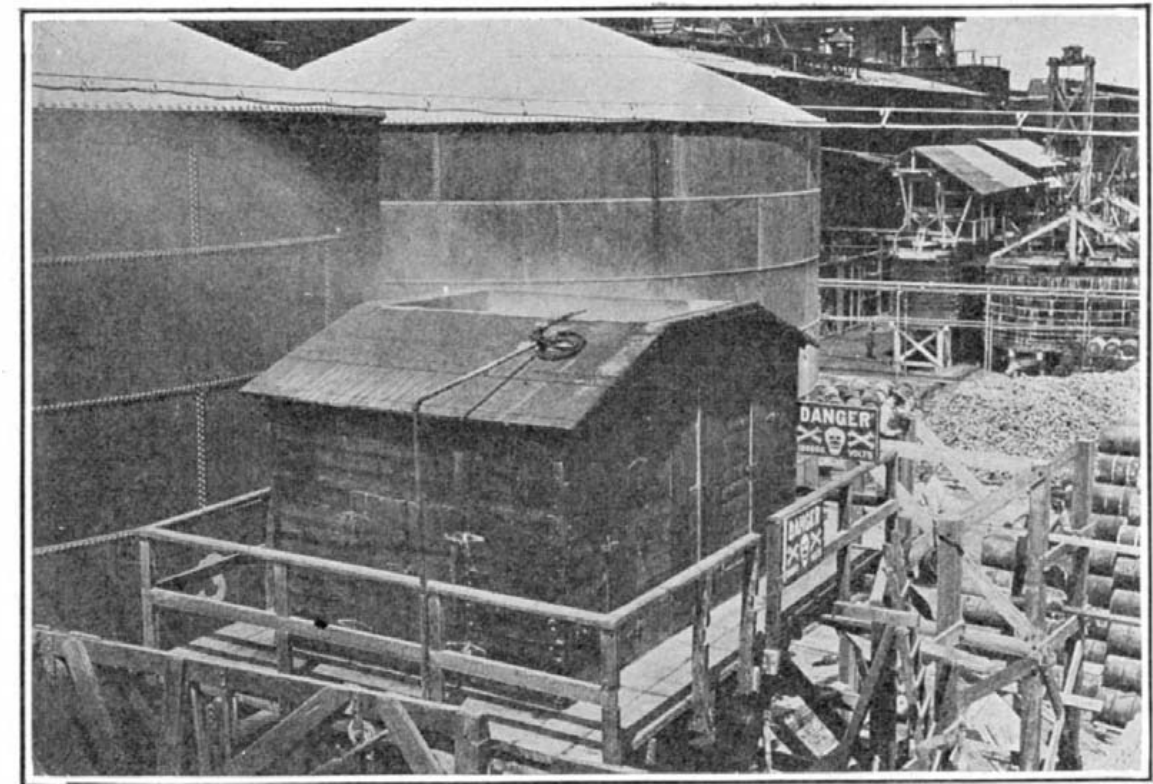

Electric precipitator for collecting dust and fumes. The danger signs serve as a reminder that the current is on, and the fumes being condensed
Not only is the briquetting process being applied to fnely divided coal, but to other materials as well. etal turnings and filings are being pressed into compact masses which can be charged into furnaces and remelted with the least possible loss. Disintegrated ores and minerals which would either blow away or which we get our meat supply are largely supported through the sale of the by-products or non-edible portions of the animals which are slaughtered. It is iterally true that here everything is utilized except the pig's squeal, the lamb's bleat and the bull's malignant bellow. Hides, hoofs, horns, hair, blood, and "in'ards" are rendered into fertilizer materials which produce large yields of grain, fruit, cotton and garden truck. In recent years a number of these by-products from the packing plants have been successfully used in stock feeds, and so many a nild bovine, blissfully unaware of her cannibalistic tendencies, is chewing a cud containing various portions of her late departed relatives.

Cotton seed is another example of where a by-product which was once considered a nuisance is now a most valuable asset. Were it not for cotton-seed oil in its many forms the cost of the housewife's shortening, salad oil, and butter substitutes would long ago have soared to heights where war prices would sound like an old-time bargain day. Even after the oil is pressed out of the cotton seed the latter still retains much of its value, for the resultant cake is now highly prized both as a fertilizer and stock feed; every year many thousand tons are returned to the soil to grow more cotton, or fed to cattle 
to enrich their milk or to enhance our meat supply. That garbage, greatest of domestic wastes, can be made to give up its values is well known to Scientific American readers through several recent articles. The housewife's next most serious bugaboo is dust, though it is doubtful if the average male will ever become sufficiently civilized to appreciate the tragedy of a slight gray film on the grand piano. A decade or so back nothing short of the dust of a precious metal was considered sufficiently interesting to warrant investigation. But we have since learned that there are many other kinds of dust which can be converted into dollars.

Curiously enough, in a number of cases wher dust has been turned from a menace into boon, its collection has actually been forced upon an unwilling industry. For instance, many of our valuabl metallic ores, particularly of copper and lead, contain very appreciable quantities of arsenic, and in smelting operations this arsenic is driven off with the furnace gases in the form of a fume or very fine dust. Until means were adopted to prevent it hese fumes were evolved from the huge smelters in our Western States and wafted over the farms and ranches in the surrounding country, with the result that the smelting companies not only had to pay large sums in damages but were confronted with the possibility of being closed down. They

sought the best technical aid and advice, and it was not long before bag houses were installed at their plants which removed from the flue gases the bulk of the poisonous dust. Thousands of tons of white arsenic are thus annually collected from the smelters through out the country and converted into pigments, compounds useful in medicine and in the dye industry and into insecticides for spraying gardens, orchards, and vineyards. Instead of being a menace to agriculture this arsenic is actually increasing crop yields by ridding our fruit and vegetables of dangerous parasites. Again, in 1920 over 10,000 tons of crude potash salts worth more than $\$ 175,000$ were recovered from the dust given off by cement $\mathrm{kilns}$ in the United States.

For years conservationists have cried out against the ruthless drain on our forests and the scandalous waste of good lumber. The Ũnited States Forest Service has done everything in its .power to stem the tide of timber exhaustion, not only by planting and guarding new forests for future generations but by teaching the present generation how to get more out of the material which has so long been burned or thrown away. If the lumberman, mill owner carpenter, builder, and cabinet maker would all

profit by the knowledge gained by the scientists at the Forest Products Laboratory we would be utilizing practically everything pertaining to timber except the knot holes. The waste of good lumber in those industries manufacturing such products as axe handles, wheel spokes, furniture, toys and agricultural implements has been and continues to be enormous. This is partly on account of the unnecessary care taken in selecting the wood, and partly due to the losses entailed in cutting small-dimension stock.

There is a tradition which has been handed down from father to son since before the days of Daniel
Boone that the sapwood of the hickory is the only proper material from which wheel spokes and axe handles should be made. Millions of feet of hickory heartwood therefore have been thrown away because it was considered unfit for use in such industries. Exhaustive tests made at the Forest Products Laboratory, however, have proven that the prejudice against the heartwood of the hickory is entirely without foundation, and thus our available supply of this type of lumber has been very greatly enhanced.

Immense possibilities in timber conservation are also offered by what is known as built-up construction,

not have to go to the expense of providing the livestock with colored glasses to persuade them that the proffered food is palatable. They eat it with relish and with profit.

White-pine sawdust, for instance, when treated with dilute sulfuric acid and cooked under pressure with steam, undergoes a chemical change and is partially converted into glucose, a simple sugar which is both digestible and nutritious. The resultant mixture, which contains from 14 to 18 per cent of glucose, is then neutralized with lime, the sugar dissolved, and the solution filtered off and boiled down under reduced ressure to the consispressure to the consismolasses is then added to the partially dried sawdust residue, and a product closely resembling bran is obtained. While considerable work must yet be done before this product is placed on the market as a standard cattle food, the experiments conducted thus far justify great expectations.

If the production of cattle food is not the aim, the processing of sawdust may be carried a step further and the sugar formed allowed to ferment so that alcohol is produced - not wood alcohol, either, but the type which once was used to rout dull care. It is estimated that $300,000,000$ gallons of alcohol could be produced from the sawdust, shavings and scraps of lumber which are annually wasted at the mill.

which consists in gluing or fastening together a number of layers of small pieces of wood to make products which were formerly constructed of single pieces of timber. Not only is this built-up stock as strong as and stronger than solid wood but it enables us to utilize vast quantities of what was formerly wood waste. Shoe lasts, hat blocks, bowling pins, wheel hubs, airplane propellers and even baseball bats have been made in this way.

Amongst the unpromising industrial wastes, sawdust has long been regarded as one of the most hopeless. Immense heaps of this material mark the location of This amount compares favorably with the world's present output of alcohol from blackstrap molasses and could be increased many fold by utilizing second-growth timber and small trees unfit for any other purpose.

Alcohol has a myriad of uses besides that which the Eighteenth Amendment was designed to squelch. In many respects it is an excellent motor fuel and while theoretically less efficient than gasoline, in actual practice it gives fully as much power per gallon and is far less likely to cause the deposition of carbon in the engine's cylinders. Eventually we must have another motor fuel to enhance or replace our fast dwindling supply of gasoline, and alcohol seems to offer the greatest promise, since it can be produced from sources which are being constantly replenished.

These are only a few of the many things we are doing toward increasing industrial efficiency. While certain factory practices might be cited which spell anything but progress, nevertheless it is evident that American industry is more or less alive to the necessity of cutting down its flagrant w a ste. Probably no other nation has been eating up its principal at a livelier rate than we, although this principal, if carefully handled, should not only

old saw mills, and it soon collects in such quantities around carpenter shops and woodworking establishments that it has to be hauled away by the truck load. But science says sawdust is full of energy, so we have decided to put it to work.

Most of us have heard the story of the economical farmer who fitted his mule with green spectacles and then fed him excelsior and sawdust in lieu of grass and ensilage. Had not the mule expired the experiment would have been a great success. Today, however, this experiment is being repeated in a modified form and with excellent results. Moreover, we do supply our needs and desires, but those of indefinite renerations. We have discovered, developed and are using our wealth, and now we are rapidly learning to save it.

The accompanying table, compiled from figures furnished by the Waste Trade Journal, gives a graphic picture of the trend of values of old materials during the past eight years. Rubber, of course, by reason of new production processes, has become more plentiful and cheaper than it was, and this is reflected in the junk prices even more than those for new rubber. Most materials maintain a goodly portion of their war-time gain. 